\title{
Trichosanthin suppresses the proliferation of glioma cells by inhibiting LGR5 expression and the Wnt/ $\beta$-catenin signaling pathway
}

\author{
JUNJIE MIAO, YILIN JIANG, DONGLIANG WANG, JINGRU ZHOU, CUNGANG FAN, \\ FENG JIAO, BO LIU, JUN ZHANG, YANGSHUO WANG and QINGJUN ZHANG \\ Department of Neurosurgery, Peking University People's Hospital, Beijing 100044, P.R. China
}

Received June 24, 2015; Accepted August 20, 2015

DOI: $10.3892 /$ or.2015.4290

\begin{abstract}
Studies have indicated that trichosanthin (TCS), a bioactive protein extracted and purified from the tuberous root of Trichosanthes kirilowii (a well-known traditional Chinese medicinal plant), produces antitumor effects on various types of cancer cells. However, the effects of TCS on glioma cells are poorly understood. The objective of this study was to investigate the antitumor effects of TCS on the U87 and U251 cell lines. The in vitro effects of TCS on these two cell lines were determined using a Cell Counting Kit-8 (CCK-8) assay, Annexin V-FITC staining, DAPI staining, Transwell assays, terminal deoxynucleotidyl transferase-mediated dUTP nick end-labeling (TUNEL) assays, 5,5',6,6'-tetrachloro-1,1',3,3'-tetraethyl-imidacarbocyanine iodide (JC-1) staining and western blotting, which was utilized to assess the expression of leucine-rich repeat-containing $\mathrm{G}$ protein-coupled receptor 5 (LGR5) and key proteins in the $\mathrm{Wnt} / \beta$-catenin signaling pathway. Our data indicated that TCS inhibited the proliferation of glioma cells in a dose- and time-dependent manner and played a role in inhibiting glioma cell invasion and migration. Additional investigation revealed that the expression levels of LGR5 and of key proteins in the $\mathrm{Wnt} / \beta$-catenin signaling pathway were markedly decreased after TCS treatment. The results suggest that TCS may induce apoptosis in glioma cells by targeting LGR5 and repressing the Wnt/ $\beta$-catenin signaling pathway. In the future, in vivo experiments should be conducted to examine the potential use of this compound as a novel therapeutic agent for gliomas.
\end{abstract}

Correspondence to: Professor Qingjun Zhang, Department of Neurosurgery, Peking University People's Hospital, 11 Xizhimen South Street, Beijing 100044, P.R. China

E-mail: zhangqjpku@163.com

Key words: trichosanthin, glioma, apoptosis, LGR5, Wnt/ß-catenin signaling

\section{Introduction}

Primary central nervous system tumors account for $2 \%$ of human malignancies (1). In general, malignant glioma is the most common type of primary intracranial tumor, and the incidence of malignant glioma is increasing worldwide, primarily as a result of improvements in diagnostic imaging (2). Despite the comprehensive treatment regimen of surgery, radiotherapy and chemotherapy, resistance to standard anti-proliferative treatment with concomitant radiotherapy and chemotherapy is common and manifests as an invasive cell population that leads to tumor recurrence and death (3). Therefore, there is an urgent need for the development of a novel agent displaying glioma-specific toxicity.

Trichosanthin (TCS), a protein of $\sim 27 \mathrm{kDa}$ that is extracted from the Chinese herb Trichosanthes kirilowii Maxim, is a type I ribosome-inactivating protein (RIP) $(4,5)$. It has been used for centuries in China as an abortifacient during early pregnancy (6). Many studies have shown that TCS has enormous potential as a therapeutic drug due to its suppression of the proliferation of various cancer cell types. Research has demonstrated that TCS restricts human choriocarcinoma cell proliferation by inducing reactive oxygen species (ROS) production $(7,8)$. In addition, TCS suppresses the proliferation of HeLa cells by blocking the PKC/MAPK signaling pathway (9) and induces the apoptosis of cervical cancer cells by increasing the intracellular $\mathrm{Ca}^{2+}$ concentration (10) and by regulating the expression of Smac (11). Moreover, previous studies have shown that TCS suppresses the proliferation of breast cancer cells and HepA-H cells by inducing cell cycle arrest and promoting apoptosis (12-14). Furthermore, research suggests that TCS induces the apoptosis of chronic myeloid leukemia cells via endoplasmic reticulum stress, the mitochondrial-dependent apoptosis pathway and the inhibition of PKC $(15,16)$. Studies have also revealed that TCS displays anti-HIV activity, as TCS is cytotoxic to HIV-infected macrophages and lymphocytes and decreases viral replication $(17,18)$. Recently, a new study showed that a peptide derived from TCS suppresses the immune response by activating $\mathrm{CD} 8^{+} \mathrm{CD} 28^{-}$regulatory $\mathrm{T}$ cells and serves as a potential therapeutic agent for immunological diseases (19). TCS not only has inhibitory activity against various tumor 
cells but also shows inhibitory activity against several normal somatic cell types, including proximal tubule epithelial cells, hepatocytes and antigen-specific T cells (20-22). Previous studies have reported that TCS can cause neurological reactions in HIV-infected patients and that such toxicity may be due to the effect of TCS on HIV-infected macrophages (23). However, intravenous injections of TCS had no toxic effects on normal mouse brain or pituitary cells (24). In conclusion, since TCS displays anticancer activity in various malignant tumors, we aimed to determine whether TCS exerts antitumor effects on glioma cells. Here, we demonstrated the anti-proliferative effects and antitumor mechanisms of action of TCS on glioma cells. Our results suggest that TCS is a novel chemotherapeutic agent that may target leucine-rich repeat-containing $\mathrm{G}$ protein-coupled receptor 5 (LGR5) and the $\mathrm{Wnt} / \beta$-catenin pathway in human glioma cells.

\section{Materials and methods}

Materials. High glucose DMEM containing fetal bovine serum (FBS), penicillin G and streptomycin was purchased from Gibco (Carlsbad, CA, USA). The U87 and U251 human malignant glioma cell lines were provided by the China Infrastructure of Cell Line Resources, (Beijing, China). TCS was purchased from Shanghai Jinshan Pharmaceutical (Shanghai, China). The primary antibodies against LGR5, $\beta$-catenin, GSK-3 $\beta$, c-myc and cyclin D1 used for western blot analysis were provided by Santa Cruz Biotechnology (Santa Cruz, CA, USA). The other reagents used in this study were of analytical grade.

Cell culture. The U87 and U251 human malignant glioma cell lines were cultured in high glucose DMEM containing $1 \%$ antibiotics and $10 \%$ FBS. The cells were cultured in an incubator at $37^{\circ} \mathrm{C}$ in $5 \% \mathrm{CO}_{2}$ and a humidified atmosphere.

Cell morphology. U87 and U251 cells were grown in culture flasks to the logarithmic growth phase. Then, the cells were treated with TCS $(20 \mu \mathrm{M})$. Morphological changes in the cells were observed using an inverted microscope, and the cells were photographed after treatment for $24 \mathrm{~h}$.

Cell viability assay. A Cell Counting Kit-8 (CCK-8) (Dojindo, Japan) assay was utilized to evaluate cell viability. U87 and U251 cells were resuspended in complete or serum-free medium at a density of $1 \times 10^{4}$ or $5 \times 10^{3}$ cells/well and were cultured in 96-well plates. The cell samples were exposed to various concentrations $(2.5,5,10,20,40$ or $80 \mu \mathrm{M})$ of TCS for 24,48 or $72 \mathrm{~h}$. After TCS treatment, the medium was removed from each well, $10 \mu \mathrm{l}$ of CCK- 8 and $100 \mu \mathrm{l}$ of serum-free medium were added, and the cells were incubated for $1 \mathrm{~h}$ at $37^{\circ} \mathrm{C}$. A microplate reader was used to measure the absorbance of each well at $450 \mathrm{~nm}$.

Detection of apoptosis via flow cytometry. The apoptosis of U87 and U251 cells was analyzed using an Annexin V-FITC apoptosis detection kit (Sigma-Aldrich, St. Louis, MO, USA). The cells were cultured with TCS $(10,20 \mu \mathrm{M})$ or vehicle (PBS) for $24 \mathrm{~h}$, and then, the cells were harvested at a density of $1 \times 10^{6}$ cells $/ \mathrm{ml}$. The cells were washed twice with ice-cold
PBS. Then, the cells $\left(1 \times 10^{6}\right)$ were resuspended in $195 \mu 1$ of binding buffer, and $5 \mu \mathrm{l}$ of Annexin V-FITC and propidium iodide (PI) were added to the cell suspension; subsequently, the cells were covered in aluminum foil and incubated at room temperature for $20 \mathrm{~min}$. After this incubation, apoptosis was analyzed via flow cytometry.

DAPI staining. After U87 glioma cells were treated with TCS (10 or $20 \mu \mathrm{M}$ ) or PBS for $24 \mathrm{~h}$, they were fixed in $4 \%$ formaldehyde and washed three times with PBS. Then, the cells were stained with DAPI staining solution $(10 \mu \mathrm{g} / \mathrm{ml})$ for $5 \mathrm{~min}$ and washed three times with PBS. The morphologic changes in the nuclei were detected using a fluorescence microscope.

Mitochondrial membrane potential measurement based on 5,5',6,6'-tetrachloro-1,1',3,3'-tetraethyl-imidacarbocyanine iodide (JC-1) staining. The decrease in mitochondrial membrane potential, which is a hallmark of apoptosis, was detected using a JC-1 mitochondrial membrane potential assay kit (Cayman Chemical, Ann Arbor, MI, USA). U87 glioma cells were treated with TCS $(10$ or $20 \mu \mathrm{M})$ or PBS for $24 \mathrm{~h}$ and then incubated in $1 \mathrm{ml}$ of JC-1 working solution for $30 \mathrm{~min}$ at $37^{\circ} \mathrm{C}$ in an incubator. These cells were washed twice with ice-cold PBS, and the fluorescence intensity of the cells was then observed via fluorescence microscopy. Decreased fluorescence of the cells was observed as the mitochondrial membrane potential collapsed.

Terminal deoxynucleotidyl transferase-mediated dUTP nick end-labeling (TUNEL) assay. DNA fragmentation was detected using a One-Step TUNEL kit (Abnova Corporation, Taipei City, Taiwan) according to the manufacturer's instructions. Briefly, after treatment with TCS $(10$ or $20 \mu \mathrm{M})$ or PBS, U87 cells were fixed in $4 \%$ paraformaldehyde for $30 \mathrm{~min}$ at room temperature. Then, the cells were washed three times with PBS and permeabilized for 2 min on ice. Next, the cells were resuspended in TUNEL working solution and incubated in a humidified atmosphere shielded from light for $1 \mathrm{~h}$ at $37^{\circ} \mathrm{C}$. Green fluorescence was detected in the FITC-labeled TUNEL-positive cells under a fluorescence microscope.

Cell migration and invasion assays. Wound healing assays were used to assess the effects of TCS on glioma cell migration. U87 cells were seeded in culture plates and incubated until they reached confluency. Subsequently, a scratch was made on the cell surface using a 10- $\mu$ l pipette tip. The cells were washed with PBS and treated with TCS $(5 \mu \mathrm{M})$ or PBS for $24 \mathrm{~h}$. The width of the wound was photographed under a microscope at 0 and $24 \mathrm{~h}$. In addition, the effect of TCS on glioma cell invasion was determined using Matrigel-coated Transwell assays. U87 cells were treated with DMEM containing TCS $(5 \mu \mathrm{M})$ or PBS for $24 \mathrm{~h}$. Then, the cells were trypsinized and seeded into the upper chamber of a Transwell insert at a density of $1 \times 10^{5}$. Medium containing $20 \%$ FBS was added to the lower chamber, and the cells were cultured for $24 \mathrm{~h}$. The cells that invaded into the outer surface of the Transwell insert were stained with $0.5 \%$ crystal violet solution and counted using an inverted microscope. 

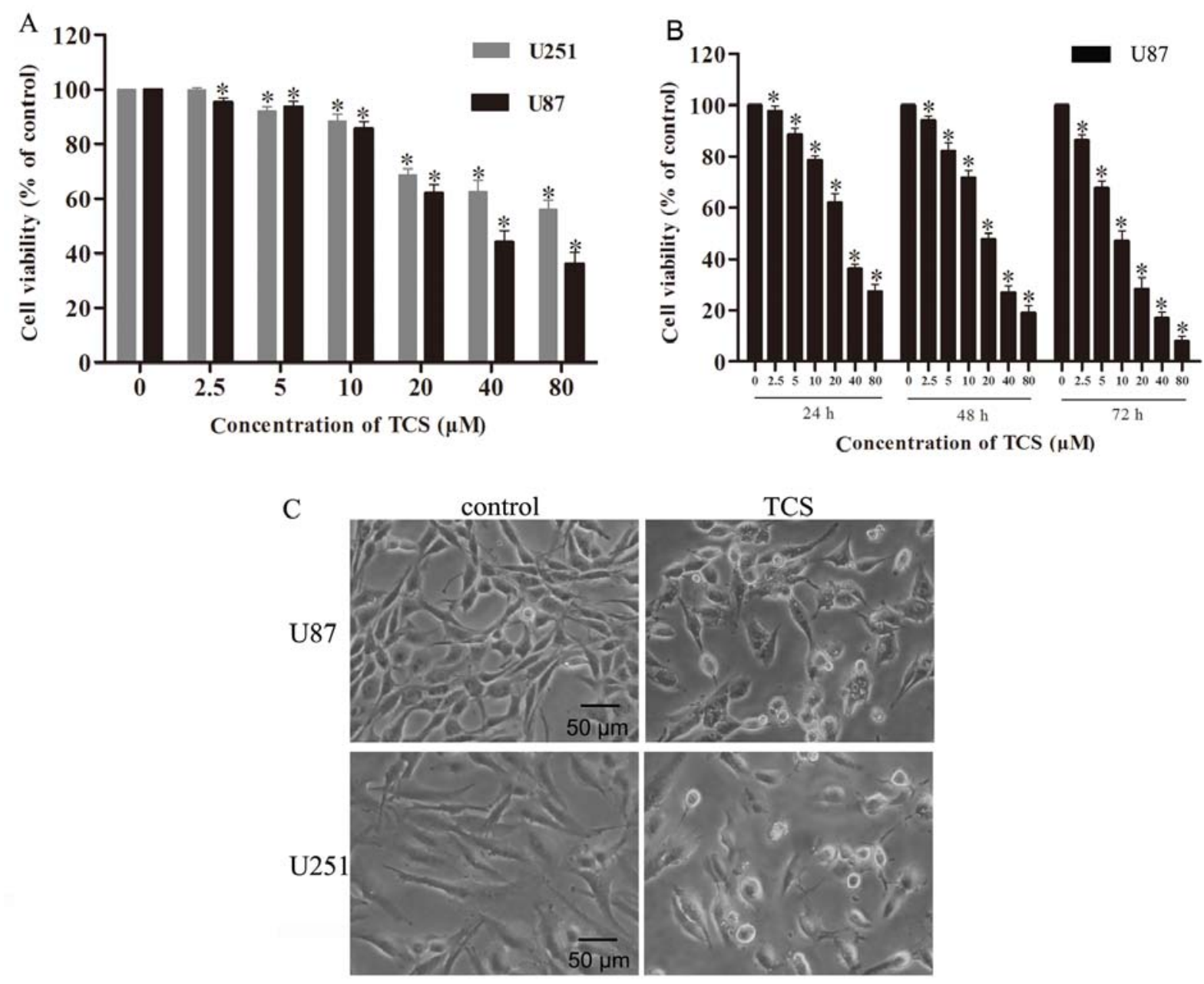

Figure 1. TCS inhibits the viability of glioma cells in a dose- and time-dependent manner. (A) Human malignant glioma cells (U87 and U251) were cultured in serum-containing DMEM in the presence of different concentrations of TCS $(0-80 \mu \mathrm{M})$ for $24 \mathrm{~h}$. The CCK- 8 assay was used to determine cell viability. The data are presented as the mean \pm SD of three independent experiments. " $\mathrm{P}<0.05$ compared with the PBS-treated (control) group. (B) U87 cells were cultured in serum-free DMEM containing various concentrations of TCS $(0-80 \mu \mathrm{M})$ for different periods $(24,48$ or $72 \mathrm{~h})$. Glioma cell viability was investigated using the CCK-8 assay. The data are presented as the mean \pm SD of three independent experiments. ${ }^{*} \mathrm{P}<0.05$ compared with the control group. (C) U87 and U251 cells were cultured in cell culture dishes and treated with DMEM containing TCS $(20 \mu \mathrm{M})$ or PBS for $24 \mathrm{~h}$. After treatment, the morphological changes in the glioma cells were observed via microscopy. Representative images from three independent experiments are shown.

Western blot analysis. Cellular proteins were extracted from glioma cells using lysis buffer [1 mM EDTA ( $\mathrm{pH} 8.0)$, $50 \mathrm{mM}$ Tris (pH 7.4), $150 \mathrm{mM} \mathrm{NaCl}, 1 \% \mathrm{NP}-40,0.1 \%$ SDS, and $0.5 \%$ sodium deoxycholate] according to the manufacturer's instructions for western blot analysis. A bicinchoninic acid protein quantitation kit (BioVision, Palo Alto, CA, USA) was used to measure the protein concentrations. The same amounts of whole-cell protein extracts from each sample were separated via SDS-PAGE and transferred to a PVDF membrane with a pore size of $0.2 \mu \mathrm{m}$. Subsequently, the membrane was blocked with 5\% milk in TBS-T for $1 \mathrm{~h}$ at room temperature (RT), incubated in a primary antibody overnight at $4^{\circ} \mathrm{C}$, and then incubated in a horseradish peroxidase-conjugated secondary antibody at room temperature for $2 \mathrm{~h}$. After washing three times with TBS, the immunoreactive bands were detected using a gel imaging analysis system after applying a chemiluminescence working solution to the PVDF membrane according to the manufacturer's instructions.

Statistical analysis. SPSS version 19.0 was utilized for the statistical analyses, and the data are presented as the mean \pm standard deviation (SD) of multiple independent experiments. Student's t-test and ANOVA were used to evaluate the differences between the means, and $\mathrm{P}<0.05$ was considered to indicate a statistically significant difference.

\section{Results}

Cell viability assay. The CCK-8 assay was used to evaluate the impact of TCS on glioma cell viability. U87 and U251 cells were treated for $24 \mathrm{~h}$ with TCS diluted to concentrations of 2.5, 5, $10,20,40$ and $80 \mu \mathrm{M}$ in complete medium; the assay results indicated that relative to the control cells, U87 cells exhibited viabilities of $95.4,93.8,85.9,62.2,44.1$ and $36.2 \%$, respectively, and U251 cells exhibited viabilities of 99.9, 92.1, 88.3, 68.8, 62.7 and 56\%, respectively ( $\mathrm{n}=4 ; \mathrm{P}<0.05)$ (Fig. 1A). In addition, the $\mathrm{IC}_{50}$ values for $\mathrm{U} 87$ and $\mathrm{U} 251$ were 40 and $51.6 \mu \mathrm{M}$, respectively. We analyzed the change in cell viability of U87 cells after treatment with TCS concentrations of 2.5, 5, 10, 20, 40 and $80 \mu \mathrm{M}$ in serum-free medium; compared with the control cells treated with PBS alone, U87 cells treated for $24 \mathrm{~h}$ exhibited viabilities of 97.7, 88.7, 78.6, 62.1, 36.2 and $27.3 \%$, respectively, 

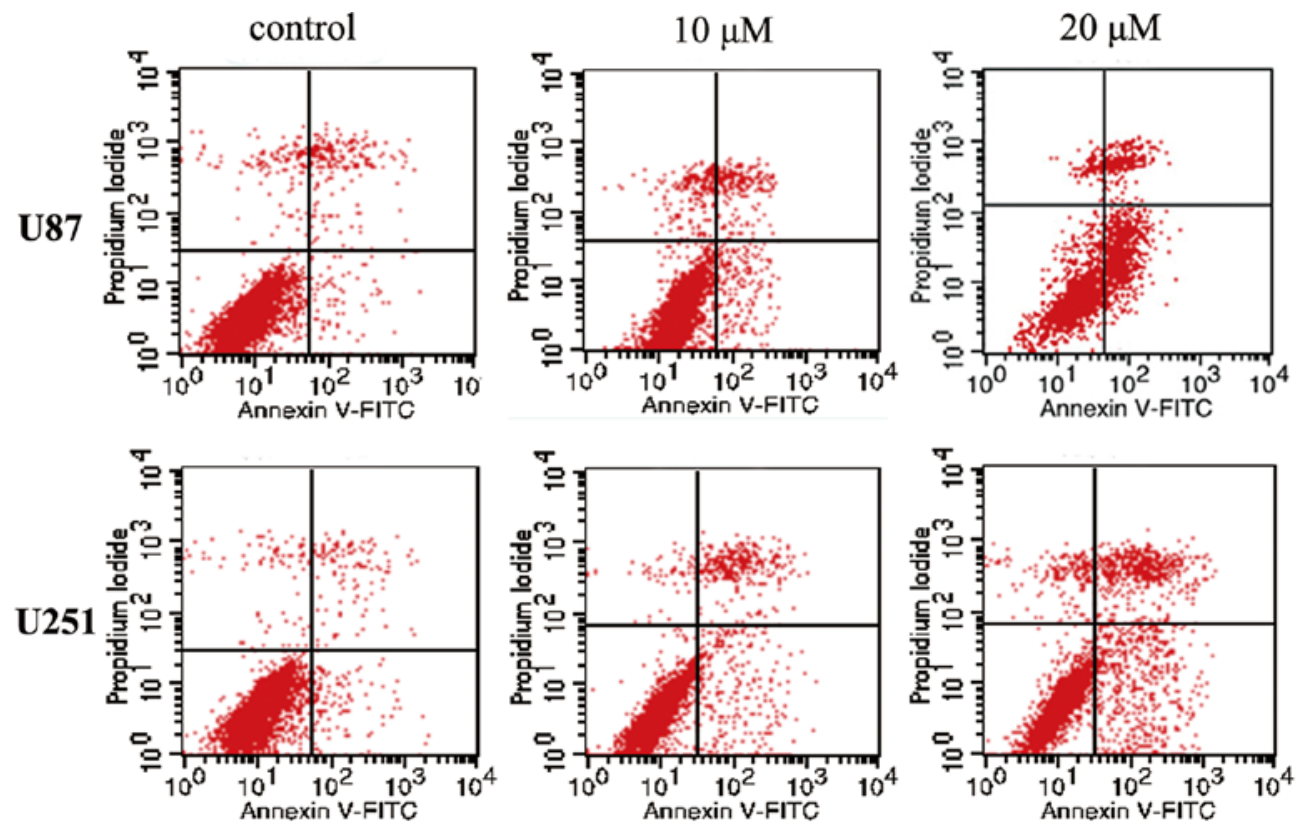

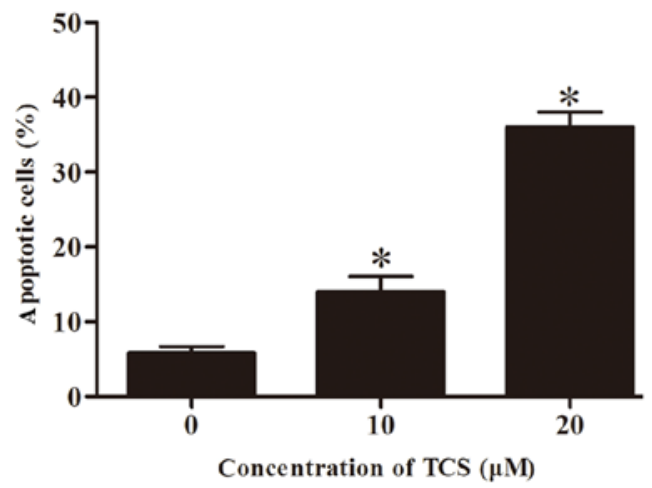

U87

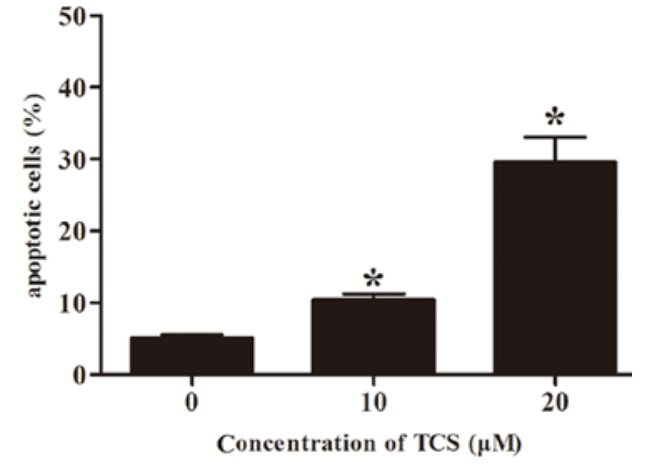

U251

Figure 2. Analysis of apoptosis via Annexin V/PI staining. U87 cells were cultured in DMEM and were treated with TCS (10, $20 \mu \mathrm{M})$ or vehicle (PBS) for $24 \mathrm{~h}$. The cells were analyzed via flow cytometry after staining with Annexin V/PI. The percentage of apoptotic cells (right lower quadrant, early apoptotic cells; right upper quadrant, late apoptotic cells) was analyzed using CellQuest Pro software. Lower graphs show the percentage of apoptotic or dead cells. * $<0.05$ compared to the respective PBS-treated (control) cells. The data are presented as the mean \pm SD of three independent experiments.

U87 cells treated for $48 \mathrm{~h}$ exhibited viabilities of 94.2, 82.3, $71.8,47.8,26.9$ and $19.0 \%$, respectively and U87 cells treated for $72 \mathrm{~h}$ exhibited viabilities of 86.3, 67.7, 47.3, 28.4, 17.0 and $7.9 \%$, respectively $(\mathrm{n}=4 ; \mathrm{P}<0.05)$ (Fig. $1 \mathrm{~B})$. The $\mathrm{IC}_{50}$ values of U87 cells for 24, 48 and 72 h of TCS treatment were 30.2 , 20.5 and $10.0 \mu \mathrm{M}$, respectively. The assay results indicated that in both the presence and the absence of serum, TCS inhibited the viability of glioma cells in a dose- and time-dependent manner.

TCS induces the apoptosis of glioma cells. To determine whether the induction of glioma cell apoptosis is related to the inhibition of proliferation, the apoptosis rate was analyzed via flow cytometry after labeling cells with Annexin V-FITC/PI. As indicated in Fig. 2, the apoptotic percentages of the U87 and U251 cells were 5.9 and 5.1\%, respectively, in the PBS-treated group; 14.1 and $10.4 \%$, respectively, in the group treated with $10 \mu \mathrm{M}$ of TCS and 36.1 and $27.8 \%$, respectively, in the group treated with $20 \mu \mathrm{M}$ of TCS. Moreover, DAPI staining was used to observe morphological variations in the nuclei, and the data showed that chromatin condensation and fragmented nuclei which are typical characteristics of apoptosis, were detected following DAPI staining when U87 cells were treated with 10, $20 \mu \mathrm{M}$ TCS for $24 \mathrm{~h}$ (Fig. 3A). Results also showed that the number of TUNEL-positive U87 cells was significantly increased in the TCS-treated group compared with the PBS treated group (Fig. 3B). Furthermore, JC-1 staining was used to visualize mitochondrial depolarization in glioma cells treated with TCS. The mitochondria of untreated JC-1-stained U87 cells emitted faint green fluorescence and strong orangered fluorescence, whereas the apoptotic cells emitted green fluorescence. Compared with the control cells treated with PBS, TCS-treated U87 cells exhibited significantly decreased mitochondrial membrane potentials, as evidenced by these cells' distinct green fluorescence (Fig. 3C).

TCS inhibits glioma cell migration and invasion. Wound healing and Matrigel-coated Transwell assays were used to evaluate the effect of TCS on migration and invasion. The percentage of wound repair decreased from 61.52 to $36.87 \%$ in response to TCS, and the ratio of invading cells on the lower side of the membrane was $42.57 \%$ after treatment with $5 \mu \mathrm{M}$ TCS compared with the control (set to $100 \%$; Fig. 4). 

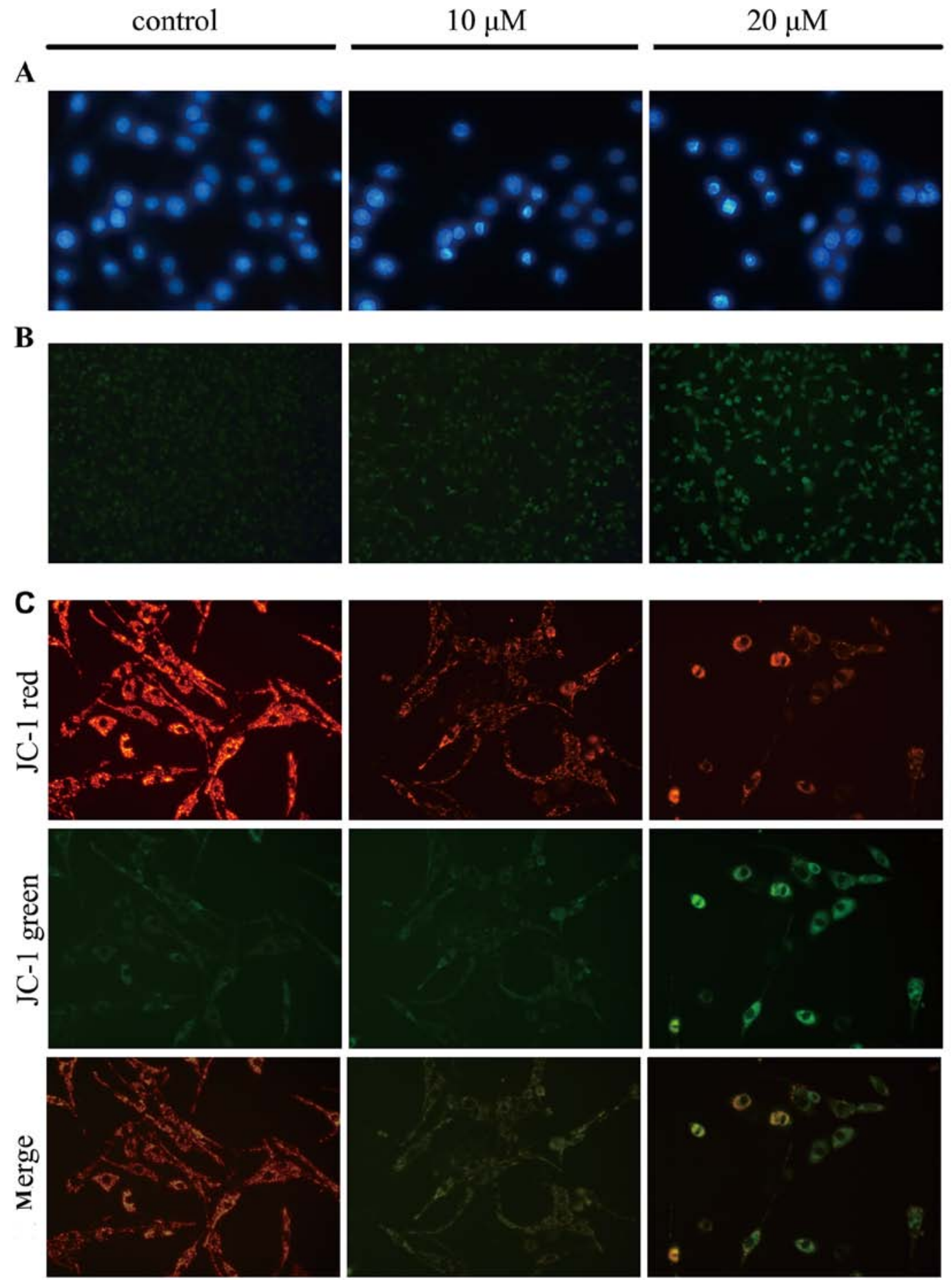

Figure 3. TCS induces apoptosis in glioma cells. (A) U87 cells were cultured in DMEM containing TCS (10,20 $\mu \mathrm{M})$ or PBS for $24 \mathrm{~h}$, and changes in nuclear morphology were observed via DAPI staining and fluorescence microscopy. The experiment was repeated three times, and the images are representative. (B) Apoptotic cells were detected via TUNEL staining. U87 cells were treated as described above prior to TUNEL staining. The number of TUNEL-positive cells was significantly increased due to TCS treatment. Representative images of TUNEL staining are shown. (C) The mitochondrial membrane potential of glioma cells was decreased due to TCS treatment. U87 cells were treated with TCS (10,20 $\mu \mathrm{M})$ or PBS for $24 \mathrm{~h}$, and the decrease in the mitochondrial membrane potential was observed based on JC-1 staining via fluorescence microscopy. The images are representative of three independent experiments.

TCS inhibits the expression of LGR5 and key proteins in the Wnt/ $\beta$-catenin signaling pathway in glioma cells. Studies have shown that LGR5 and the Wnt/ $\beta$-catenin signaling pathway play crucial roles in the proliferation, differentiation and metastasis of cancers of varying origin (25). To further explore the suppressive mechanism of action of TCS in glioma cells, we examined the expression levels of LGR5 by immu- noblotting. As shown in Fig. 5, as the TCS dose increased $(0-20 \mu \mathrm{M} ; 24 \mathrm{~h})$, the levels of LGR5 protein expression in the U87 cells markedly decreased. We also analyzed the protein levels of phosphorylated glycogen synthase kinase- $3 \beta$ (pGSK-3 ${ }^{\text {ser9 }}$ ), $\beta$-catenin, c-myc and cyclin D1, which are key members of the Wnt/ $\beta$-catenin signaling pathway, via western blot analysis, and we found that increasing concentrations of 
A
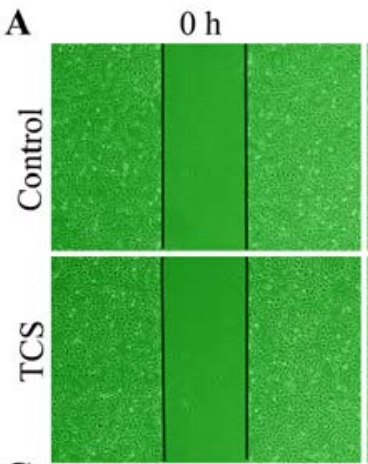

C

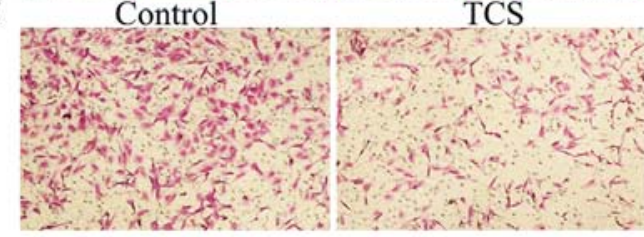

$24 \mathrm{~h}$
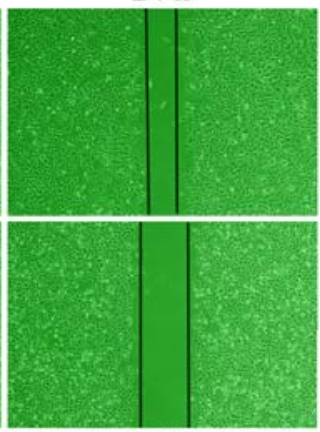

TCS
B

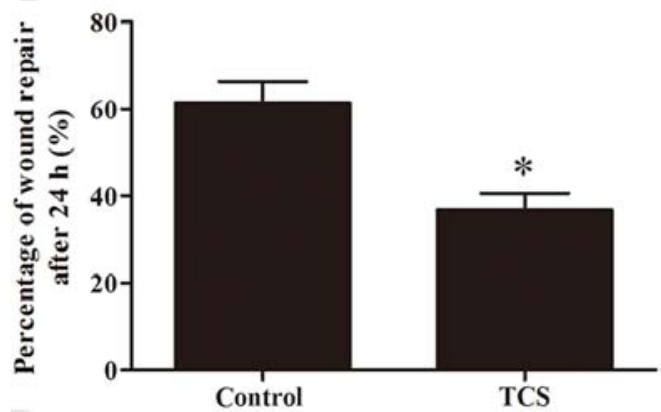

D

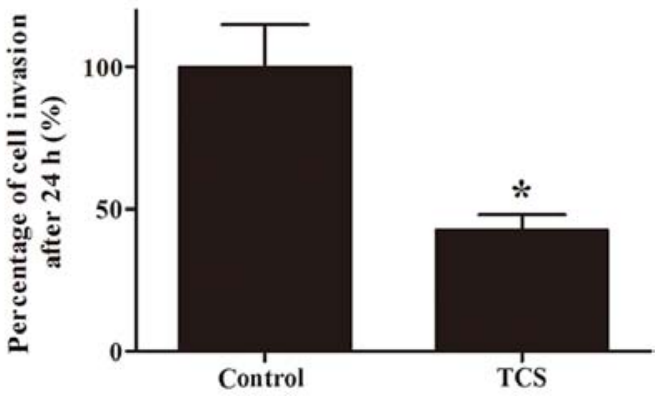

Figure 4. TCS inhibits glioma cell migration and invasion in vitro. The effects of TCS on U87 cell migration were assessed using wound healing assays. (A) Representative images of wound healing at 0 and $24 \mathrm{~h}$. (B) Quantification of the wound healing assays after U87 cells were treated with TCS (5 $\mu \mathrm{M}$ ) or vehicle (PBS) for 0 and $24 \mathrm{~h}$. ${ }^{*} \mathrm{P}<0.05$. Matrigel-coated Transwell assays were used to analyze U87 cell invasion. (C) Representatives images of cells that migrated through the Matrigel-coated Transwell inserts. (D) Histogram indicating the percentage of invasive cells compared with the control group. ${ }^{*}<0.05$.

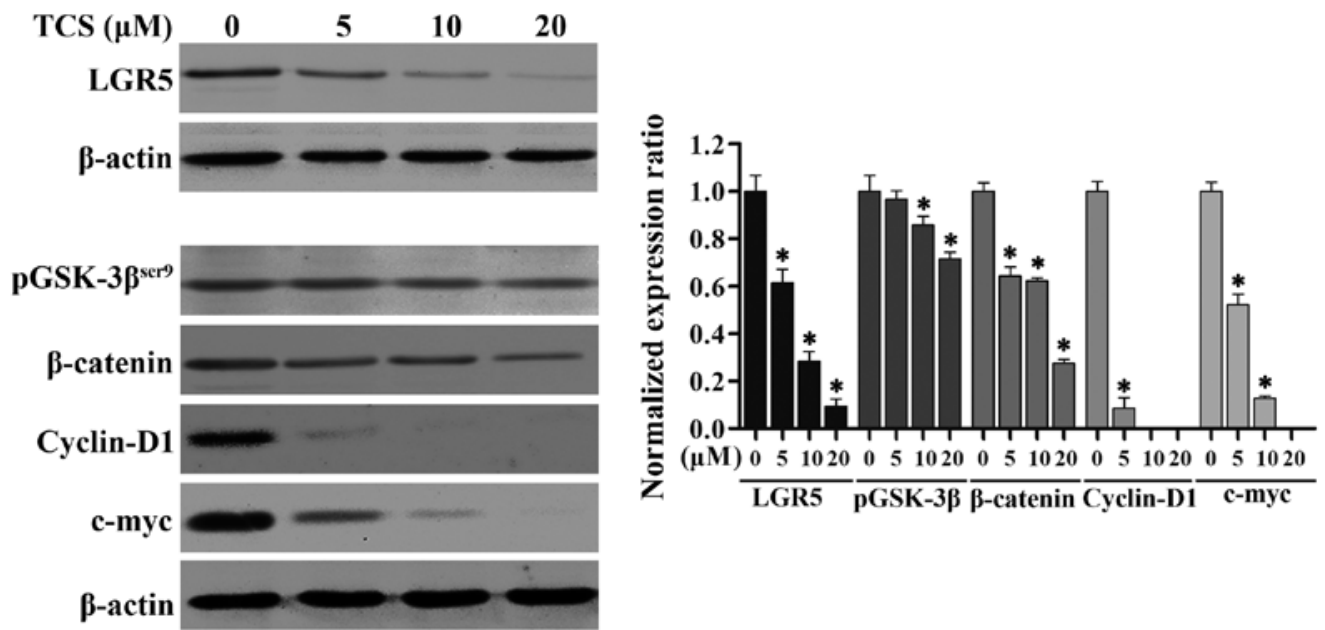

Figure 5. Western blot analysis of LGR5 and Wnt/ $\beta$-catenin signaling pathway proteins. U87 cells were treated with different concentrations of TCS $(5,10$, or $20 \mu \mathrm{M}$ ) or vehicle (PBS) for $24 \mathrm{~h}$. Protein samples were obtained from the four groups and were analyzed via western blot analysis. The results showed that the protein levels of LGR5 and key members of the Wnt/ $\beta$-catenin signaling pathway (pGSK- $3 \beta^{\text {Ser9 }}, \beta$-catenin, c-myc and cyclin D1) were downregulated in response to increasing TCS concentrations. Right panel, quantitative analysis of protein expression from three independent experiments. "P<0.05 compared with the control group.

TCS $(0-20 \mu \mathrm{M} ; 24 \mathrm{~h})$ resulted in an evident downregulation of these proteins (Fig. 5). Taken together, these results demonstrated that TCS treatment reduces the expression of LGR5 and key proteins in the $\mathrm{Wnt} / \beta$-catenin signaling pathway in a dose-dependent manner in glioma cells.

\section{Discussion}

Malignant gliomas account for the majority of primary brain tumors (26). The development of neuroimaging has allowed for the early diagnosis of these gliomas, and standard treatment with surgery, chemotherapy and radiation can be provided; however, patients with malignant gliomas nonetheless have poor prognoses. According to research data, the median survival duration for malignant glioma patients after treatment is less than one year (27). Therefore, neurosurgical studies of malignant gliomas have long focused on finding more effective treatment approaches. As a newly discovered active constituent of natural products, TCS has drawn a great deal of research attention due to its antitumor effects. In the present 
study, we demonstrated for the first time that TCS produces anti-glioma effects by inhibiting cell viability, migration, and invasion and by inducing apoptosis. Our results revealed that TCS significantly inhibited the proliferation of the U87 and U251 cell lines, which contain large numbers of glioma stem cells, in a dose- and time-dependent manner. The $\mathrm{IC}_{50}$ values for U87 cells were lower than the corresponding $\mathrm{IC}_{50}$ values for U251 cells, indicating that U87 cells were more vulnerable than U251 cells to TCS. Therefore, U87 cells were selected for additional experimentation.

Prior research has demonstrated that inducing apoptosis in tumor cells is an important mechanism of action for many antitumor drugs. In our study, flow cytometry revealed that apoptosis occurred in glioma cells after TCS treatment. Consistent with this finding, different typical morphological characteristics of apoptotic cells, including the condensation and clustering of chromatin along the nuclear membrane, internucleosomal DNA fragmentation and a decrease in mitochondrial membrane potential, were detected in the TCS-treated U87 cells by DAPI staining, a TUNEL assay, and JC-1 staining, respectively. These results suggest that TCS inhibits the proliferation of malignant glioma cells by inducing apoptosis.

However, the mechanism by which TCS induces apoptosis in malignant glioma cells has not been well established. LGR5, a member of the $G$ protein-coupled receptor family (28), plays an important role in embryonic development and is widely expressed in brain and spinal cord tissue $(29,30)$. Recent studies have revealed that the overexpression of LGR5 promotes the survival and growth of different types of tumors, including colorectal carcinomas, Ewing's sarcomas and glioblastomas (31-33). Furthermore, in our previous research, we found that LGR5 expression was closely associated with the pathologic grade of gliomas; moreover, the knockdown of LGR5 was found to inhibit the proliferation of U87 cells and suppresses the growth of xenografts (34). In the present study, our findings demonstrated that TCS treatment significantly reduce the levels of LGR 5 , pGSK- $3 \beta^{\text {Ser9 }}, \beta$-catenin, c-myc and cyclin D1 in the U87 cells. It has been well established that LGR5, pGSK-3 $\beta^{\text {Ser9 }}, \beta$-catenin, c-myc and cyclin D1 are important proteins of the $\mathrm{Wnt} / \beta$-catenin pathway, which is intimately involved in normal development and the regulation of cancer stem cells (35). LGR5 binds to Wnt, low-density lipoprotein receptor-related protein (LRP) and frizzled (FZD) after interaction with the ligand R-spondin (RSPO); the resulting complex promotes the phosphorylation of GSK-3 $\beta^{\text {Ser9 }}$ and inhibits the phosphorylation of $\beta$-catenin (36). Unphosphorylated $\beta$-catenin translocates to the nucleus and interacts with transcription factors, activating the expression of downstream genes such as c-myc and cyclin D1 and ultimately promoting cell proliferation (37). Research has reported that in colorectal cancer cells, the depletion of LGR5 can decrease the expression of c-myc and cyclin D1, which are downstream target genes of the $\mathrm{Wnt} / \beta$-catenin pathway, and induce apoptosis via an intrinsic apoptosis pathway (38). Therefore, we believe that suppression of LGR5 expression and of the $\mathrm{Wnt} / \beta$-catenin signaling pathway may be the mechanism by which TCS induces apoptosis in U87 cells. However, understanding the detailed mechanism will require further study.
Further studies of the efficacy of TCS in in vivo models are needed to confirm our findings, although our results have demonstrated that TCS can induce apoptosis and inhibit the invasive/metastatic potential of glioma cells; thus, this study has revealed a novel concept for the treatment of malignant gliomas.

\section{Acknowledgements}

We thank Dr Weidong Yu and Mrs. Xin Yu for providing technical assistance with western blotting, fluorescence microscopy and FACS. We would also like to thank Dr Xiangjun He and Mrs. Mei Li for providing laboratory equipment. We thank American Journal Experts (AJE) for English language editing. This study was supported by the Peking University People's Hospital Research and Development Funds (no. RDB2011-14) and by the National Natural Science Foundation of China (no. 81001009).

\section{References}

1. Jansen M, Yip S and Louis DN: Molecular pathology in adult gliomas: Diagnostic, prognostic, and predictive markers. Lancet Neurol 9: 717-726, 2010.

2. Wen PY and Kesari S: Malignant gliomas in adults. N Engl J Med 359: 492 507, 2008.

3. Fortin Ensign SP, Mathews IT, Symons MH, Berens ME and Tran NL: Implications of Rho GTPase signaling in glioma cell invasion and tumor progression. Front Oncol 3: 241, 2013.

4. Maraganore JM, Joseph M and Bailey MC: Purification and characterization of trichosanthin. Homology to the ricin A chain and implications as to mechanism of abortifacient activity. J Biol Chem 262: 11628-11633, 1987.

5. Zhang XJ and Wang JH: Homology of trichosanthin and ricin A chain. Nature 321: 477-478, 1986.

6. Sha O, Niu J, Ng TB, Cho EY, Fu X and Jiang W: Antitumor action of trichosanthin, a type 1 ribosome-inactivating protein, employed in traditional Chinese medicine: A mini review. Cancer Chemother Pharmacol 71: 1387-1393, 2013.

7. Zhang CY, Gong YX, Ma H, An CC and Chen DY: Trichosanthin induced calcium-dependent generation of reactive oxygen species in human choriocarcinoma cells. Analyst 125: 1539-1542, 2000.

8. Zhang C, Gong Y, Ma H, An C, Chen D and Chen ZL: Reactive oxygen species involved in trichosanthin-induced apoptosis of human choriocarcinoma cells. Biochem J 355: 653-661, 2001.

9. Wang P, Chen LL, Yan H and Li JC: Trichosanthin suppresses HeLa cell proliferation through inhibition of the PKC/MAPK signaling pathway. Cell Biol Toxicol 25: 479-488, 2009.

10. Wang P, Xu S, Zhao K, Xiao B and Guo J: Increase in cytosolic calcium maintains plasma membrane integrity through the formation of microtubule ring structure in apoptotic cervical cancer cells induced by trichosanthin. Cell Biol Int 33: 1149-1154, 2009.

11. Cui L, Song J, Wu L, Huang L, Wang Y, Huang Y, Yu H, Huang Y, You CC and Ye J: Smac is another pathway in the anti-tumour activity of trichosanthin and reverses trichosanthin resistance in CaSki cervical cancer cells. Biomed Pharmacother 69: 119-124, 2015.

12. Dou CM and Li JC: Effect of extracts of trichosanthes root tubers on HepA-H cells and HeLa cells. World J Gastroenterol 10: 2091-2094, 2004.

13. Fang EF, Zhang CZ, Zhang L, Wong JH, Chan YS, Pan WL, Dan XL, Yin CM, Cho CH and Ng TB: Trichosanthin inhibits breast cancer cell proliferation in both cell lines and nude mice by promotion of apoptosis. PLoS One 7: e41592, 2012.

14. Zheng YT, Zhang WF, Ben KL and Wang JH: In vitro immunotoxicity and cytotoxicity of trichosanthin against human normal immunocytes and leukemia-lymphoma cells. Immunopharmacol Immunotoxicol 17: 69-79, 1995.

15. Li J, Xia X, Ke Y, Nie H, Smith MA and Zhu X: Trichosanthin induced apoptosis in HL-60 cells via mitochondrial and endoplasmic reticulum stress signaling pathways. Biochim Biophys Acta 1770: 1169-1180, 2007. 
16. Li J, Xia X, Nie H, Smith MA and Zhu X: PKC inhibition is involved in trichosanthin-induced apoptosis in human chronic myeloid leukemia cell line K562. Biochim Biophys Acta 1770: 63-70, 2007.

17. Byers VS, Levin AS, Malvino A, Waites L, Robins RA and Baldwin RW: A phase II study of effect of addition of trichosanthin to zidovudine in patients with HIV disease and failing antiretroviral agents. AIDS Res Hum Retroviruses 10: 413-420, 1994.

18. McGrath MS, Hwang KM, Caldwell SE, Gaston I, Luk KC, Wu P, Ng VL, Crowe S, Daniels J and Marsh J: GLQ223: An inhibitor of human immunodeficiency virus replication in acutely and chronically infected cells of lymphocyte and mononuclear phagocyte lineage. Proc Natl Acad Sci USA 86: 2844-2848, 1989

19. Yang N, Li Z, Jiao Z, Gu P, Zhou Y, Lu L and Chou KY: A Trichosanthin-derived peptide suppresses type 1 immune responses by TLR2-dependent activation of CD8(+)CD28(-) Tregs. Clin Immunol 153: 277-287, 2014.

20. Tang NL, Chan WL, Ke YO, Mak MK, Lai FM and Tam SC: Acute renal failure and proximal tubule lesions after trichosanthin injection in rats. Exp Mol Pathol 64: 78-89, 1997.

21. Li F, Mei Y, Wang Y, Chen C, Tu J, Xiao B and Xu L: Trichosanthin inhibits antigen-specific $\mathrm{T}$ cell expansion through nitric oxide-mediated apoptosis pathway. Cell Immunol 234 23-30, 2005.

22. Ng TB, Liu WK, Tsao SW and Yeung HW: Effect of trichosanthin and momorcharins on isolated rat hepatocytes. J Ethnopharmacol 3: 81-87, 1994.

23. Garcia PA, Bredesen DE, Vinters HV, Graefin von Einsiedel R Williams RL, Kahn JO, Byers VS, Levin AS, Waites LA and Messing RO: Neurological reactions in HIV-infected patients treated with trichosanthin. Neuropathol Appl Neurobiol 19: 402-405, 1993.

24. Ng TB, Kwong WH and Yeung HW: Intravenous injections of the ribosome inactivating protein trichosanthin did not affect methionine enkephalin and $\beta$-endorphin levels in the mouse brain and pituitary. Biochem Mol Biol Int 39: 985-989, 1996.

25. Rot S, Taubert H, Bache M, Greither T, Würl P, Eckert AW, Schubert J, Vordermark D and Kappler M: A novel splice variant of the stem cell marker LGR5/GPR49 is correlated with the risk of tumor-related death in soft-tissue sarcoma patients. BMC Cancer 11: 429, 2011

26. Stewart LA: Chemotherapy in adult high-grade glioma: A systematic review and meta-analysis of individual patient data from 12 randomised trials. Lancet 359: 1011-1018, 2002.

27. Bleehen NM and Stenning SP; The Medical Research Council Brain Tumour Working Party: A Medical Research Council trial of two radiotherapy doses in the treatment of grades 3 and 4 astrocytoma. Br J Cancer 64: 769-774, 1991.
28. Hsu SY, Liang SG and Hsueh AJ: Characterization of two LGR genes homologous to gonadotropin and thyrotropin receptors with extracellular leucine-rich repeats and a $\mathrm{G}$ protein-coupled, seven-transmembrane region. Mol Endocrinol 12: 1830-1845, 1998.

29. Hsu SY, Kudo M, Chen T, Nakabayashi K, Bhalla A, van der Spek PJ, van Duin $M$ and Hsueh AJ: The three subfamilies of leucine-rich repeat-containing $\mathrm{G}$ protein-coupled receptors (LGR): Identification of LGR6 and LGR7 and the signaling mechanism for LGR7. Mol Endocrinol 14: 1257-1271, 2000.

30. Barker $\mathrm{N}$ and Clevers $\mathrm{H}$ : Leucine-rich repeat-containing G-protein-coupled receptors as markers of adult stem cells. Gastroenterology 138: 1681-1696, 2010.

31. McClanahan T, Koseoglu S, Smith K, Grein J, Gustafson E, Black S, Kirschmeier P and Samatar AA: Identification of overexpression of orphan $\mathrm{G}$ protein-coupled receptor GPR49 in human colon and ovarian primary tumors. Cancer Biol Ther 5: 419-426, 2006

32. Scannell CA, Pedersen EA, Mosher JT, Krook MA, Nicholls LA, Wilky BA, Loeb DM and Lawlor ER: LGR5 is expressed by Ewing sarcoma and potentiates Wnt/beta-catenin signaling. Front Oncol 3: 81, 2013

33. Nakata S, Campos B, Bageritz J, Bermejo JL, Becker N, Engel F, Acker T, Momma S, Herold-Mende C, Lichter P, et al: LGR5 is a marker of poor prognosis in glioblastoma and is required for survival of brain cancer stem-like cells. Brain Pathol 23: 60-72, 2013.

34. Wang D, Zhou J, Fan C, Jiao F, Liu B, Sun P, Miao J and Zhang Q: Knockdown of LGR5 suppresses the proliferation of glioma cells in vitro and in vivo. Oncol Rep 31: 41-49, 2014.

35. Wend P, Holland JD, Ziebold U and Birchmeier W: Wnt signaling in stem and cancer stem cells. Semin Cell Dev Biol 21: 855-863, 2010.

36. Glinka A, Dolde C, Kirsch N, Huang YL, Kazanskaya O, Ingelfinger D, Boutros $M$, Cruciat CM and Niehrs C: LGR4 and LGR5 are R-spondin receptors mediating Wnt/ $\beta$-catenin and Wnt/PCP signalling. EMBO Rep 12: 1055-1061, 2011.

37. Anna CH, Iida M, Sills RC and Devereux TR: Expression of potential beta-catenin targets, cyclin D1, c-Jun, c-Myc, E-cadherin, and EGFR in chemically induced hepatocellular neoplasms from B6C3F1 mice. Toxicol Appl Pharmacol 190: 135-145, 2003.

38. Hsu HC, Liu YS, Tseng KC, Tan BC, Chen SJ and Chen HC: LGR5 regulates survival through mitochondria-mediated apoptosis and by targeting the Wnt/ $\beta$-catenin signaling pathway in colorectal cancer cells. Cell Signal 26: 2333-2342, 2014. 